\title{
ARTIGOS
}

\section{PREDICAÇÃO E JUÍZO EM TOMÁS DE AQUINO}

Raul Landim Filho* raullandim@uol.com.br

RESUMO Neste artigo, pretendemos expor uma interpretação da teoria tomásica do juízo assertórico (enunciado), analisando os aspectos semânticos, epistêmicos e ontológicos dessa teoria. São explicitados os elementos constitutivos do juizo: conceito, imagem, predicação (composição e divisão), reflexão, afirmação, negação, verdadeiro e falso. $O$ artigo mostra que, interpretada dessa forma, a teoria do juízo pode contribuir para o esclarecimento das distinções que serão tematizadas pela metafísica tomásica: as distinções entre ser, ente, essência e existência.

Palavras-Chave Conceito, Predicação, Reflexão, Afirmação, Juizo

ABSTRACT In this paper, we intend to present an interpretation of Thomas Aquinas's theory of judgment (statement), examining semantical, epistemological and ontological aspects of this theory. Elements of judgment such as concepts, phantasms, predication (combination and division), reflection, affirmation, truth and falsity are explained. The article shows that this interpretation of Aquinas's theory of judgment may contribute to clarify fundamental distinctions (as the distinctions between being, essence and existence) of Aquinas's metaphysics.

Keywords Concept, Predication, Reflection, Affirmation, Judgment

* Professor titular do Departamento de Filosofia da Universidade Federal do Rio de Janeiro e pesquisador do CNPq. Artigo recebido em dez./05 e aprovado em maio/06. 
Dedico este artigo a Henrique Vaz s. j., filósofo, mestre e amigo, falecido em maio de 2002, que escreveu sobre o tema deste trabalho dois textos magistrais: "Itinerário da Ontologia Clássica" e "Tomás de Aquino: Pensar a Metafísica na Aurora de um Novo Século".

A partir do século XX, o neotomismo deu especial ênfase à teoria do juízo tomásica. Foram múltiplas e, muitas vezes divergentes, as razões dessa ênfase: certas interpretações procuraram mostrar que o ato judicativo é o ponto de partida da metafísica ${ }^{2}$; outras interpretações, com preocupações diferentes, defenderam a tese de que a noção central da metafísica tomásica é o ser e não o ente, e o ser, ao contrário do ente, é uma noção que não é captada por um conceito qüididativo, mas apenas por um juízo ${ }^{3}$; outras ainda, oriundas do quadro conceitual da filosofia analítica, tentaram aproximar a análise do juízo tomásica à lógica filosófica contemporânea, dando uma inesperada atualidade a certas reflexões semânticas de Tomás que tinham caído em desuso ${ }^{4}$.

Neste artigo, pretendemos expor sinteticamente a teoria do juízo tomásica ${ }^{5}$, o que, sem dúvida, pode ser considerado temerário face à multiplicidade de aspectos semânticos, epistêmicos e ontológicos por ela envolvidos. É a sutileza dessa teoria que nos faz correr esse risco.

\section{Análise lingüística: nome, verbo e enunciado}

Na filosofia tomásica o termo "juízo" tem vários sentidos. ${ }^{6}$ A noção de juízo que será analisada neste artigo é a de "juízo por composição e divisão", pois só nesse sentido, juízo tem valor de verdade.

1 VAZ, 1996, p. 159-207.

2 Ver o "tomismo transcendental", cuja obra fundamental é a de MARÉCHAL, 1949. E que teve em K. Rahner, J. de Finance e A. Marc os seus mais conhecidos seguidores.

3 Ver o "tomismo existencial", cujo texto fundamental é o livro de GILSON, 1948. Uma versão em inglês desse livro foi publicada com o título Being and some philosophers. A segunda edição desse livro contém um importante Apêndice com uma crítica à interpretação de Gilson, de L. M. Régis, e com resposta do próprio Gilson. J. Maritain, L. Geiger, J. Owens e outros participaram, a seu modo, dessa linha de interpretação. Ver também a penetrante crítica ao "tomismo existencial" de McINERNY, 1986, p. 173-228. WIPPEL, embora não possa ser considerado como um "tomista existencial", concorda com muitas teses dessa escola. Ver, por exemplo, o seu livro The metaphysical thought of Thomas Aquinas, p. 21-62.

4 Ver ANSCOMBE e GEACH, 1961. Geach publicou inúmeros artigos sobre a filosofia de Tomás. Ver, especialmente: GEACH, 1969, p. 42-64.

5 Neste artigo, não analisaremos a questão da intelecção dos "primeiros princípios" e a função deles na constituição da ciência demonstrativa. De fato, os primeiros princípios são "normas reguladoras e constitutivas" do ato intelectual. (Ver, por exemplo, a função do princípio de contradição na apreensão qüididativa e na operação judicativa de composição e de divisão). Mas a abordagem dessa questão envolve a análise do problema da "iluminação" do intelecto humano pelo intelecto divino ou a da participação do intelecto humano no intelecto divino. $\mathrm{O}$ estudo desses temas transcende o objetivo deste artigo na medida em que impõe uma reflexão pormenorizada sobre a natureza qüididativa do intelecto humano e a do intelecto em geral. GARCEAU, 1968, p. 101-152 e 265-278. 
Juízos por composição e divisão são atos mentais. Como, então, analisá-los?

Tomás de Aquino assume a validade do célebre triângulo ${ }^{1}$ semântico formulado por Aristóteles ${ }^{1}$ no De interpretatione: as palavras escritas significam por convenção os sons orais, que, por sua vez, significam por convenção paixões da alma (conceitos, segundo Tomás) que por natureza são similitudes de coisas. Se um signo escrito ou oral é simples (sem partes significativas) e significa, por convenção, atemporalmente, conceitos (que, por sua vez, são similitudes de coisas), esse signo é denominado nome. Um signo simples que convencionalmente significa, de maneira temporal, ações ou propriedades é denominado verbo. Verbos são signos de coisas ditas de alguma outra coisa ${ }^{2}$. Por isso, são expressões incompletas, na medida em que exigem o complemento de um nome para formar uma oração predicativa.

As análises tomásicas sobre nomes e verbos, tal como ocorre no $D e$ interpretatione de Aristóteles, flutuam entre uma caracterização meramente gramatical dessas expressões ${ }^{3}$ (nome seria um signo oral convencional, sem partes significativas etc.) e uma caracterização funcional: nomes exerceriam a função de sujeito da oração predicativa; verbos, a de predicados; sujeitos teriam a função de mencionar coisas; predicados, de caracterizá-las. ${ }^{4}$ Embora sujeito e predicado sejam funções logicamente heterogêneas e complementares, nomes podem exercer a função de predicado e verbos (ao menos no infinitivo e no particípio) podem exercer a função de sujeito. Essas ambigüidades que surgem do fato de que nome não pode ser identificado com a função de sujeito e verbo com a de predicado repercutem na análise do verbo "ser" nos Comentários de Tomás ao De interpretatione: ${ }^{5}$ ser pode ser interpretado como nome, significando ente (o que é), portanto, significando, coisas (objetos); pode ser interpretado como predicado (significando propriedades de coisas): seja como parte de um predicado complexo, exprimindo a inerência de propriedades nas coisas que foram mencionadas pelo sujeito (ser como cópula), ${ }^{6}$ seja como um predicado simples, significando a existência factual das coisas mencionadas pelo sujeito (ser como existência

1 ARISTÓTELES, 2002.

2 De interpretatione, op. cit., $16^{\mathrm{b}} 8$.

3 Idem, op. cit., 16 $19-20$ e $16^{\text {a }} 32-16^{\text {b }} 7$.

4 Ver a análise de Geach sobre as noções de sujeito e de predicado que se apóiam nos comentários de Tomás sobre o De interpretatione: GEACH, 1968, p. 22-44.

5 Peryermenias, op. cit., I, cap. 5, p. 30-31.

6 "(...) daí que quando queremos significar que qualquer forma ou ato está atualmente (inesse) em algum sujeito, significamos isso por este verbo é ou sem qualificação (simpliciter) segundo o tempo presente ou com uma qualificação (secundum quid), mas segundo outros tempos" (Peryermenias, op. cit., I, cap. 5, p. 31, grifo no original). 
factual) $;^{1}$ finalmente essas considerações semânticas sugerem uma análise "metafísica": ser pode significar o ato pelo qual algo (o ente) é. ${ }^{2}$

Orações, diferentemente de nomes e de verbos, são expressões convencionais complexas, pois suas partes, tomadas isoladamente, são significativas. Mas, conectar ou aplicar um verbo a um nome é formar uma oração predicativa, pois predicar é atribuir uma propriedade a uma coisa. Nomes e verbos são "termos gramaticais"; mas, numa oração predicativa, nomes exercem prioritariamente a função lógica de sujeito; verbos, a de predicado; o nome-sujeito significa (mediante um conceito) uma coisa (objeto), que é caracterizada por uma propriedade significada pelo verbo-predicado. ${ }^{3}$ Portanto, não há predicação elementar sem composição do predicado com o sujeito (do verbo com nome). São denominadas enunciados as orações predicativas que têm valor de verdade. Nome/verbo e enunciado exprimem do ponto de vista lingüístico as operações mentais, denominadas por Tomás, de intelecção dos indivisíveis e de juízo por composição e divisão. Graças à correspondência entre as operações lingüísticas e as operações do intelecto correspondentes, é possível analisar lingüisticamente o ato judicativo sem recorrer a métodos introspectivos.

\section{Termos gerais e conceitos}

Segundo Tomás, conhecer é julgar: “É preciso dizer que em qualquer conhecimento há um duplo aspecto: o princípio e o termo. Com efeito, o princípio pertence à apreensão, o termo, porém, ao juízo; de fato aí o conhecimento é realizado (perficitur)". ${ }^{4}$

Nesse texto, além de afirmar que só no juízo o conhecimento se realiza, Tomás distingue as duas operações, já mencionadas, do intelecto: a apreensão e o juízo. Em diversos outros textos, ${ }^{5}$ Tomás tematiza essa distinção e as denomina de intelecção dos indivisíveis ( $1^{\mathrm{a}}$ operação do intelecto) e de composição

1 Geach afirma que Tomás de Aquino distingue dois tipos de enunciados "existenciais": os da forma "Há um x que é P" e os da forma S existe. Os enunciados que têm a primeira forma responderiam à questão an sit e significam o ente veritativo, isto é, a verdade de um enunciado categórico afirmativo. A distinção entre esses dois gêneros de enunciados existenciais permitiria explicar o sentido dos enunciados existenciais verdadeiros cujo sujeito menciona privações como, por exemplo, "A cegueira existe". Esse enunciado significa um ente veritativo, não categorial, e equivaleria ao enunciado Há algo que é cego. Enunciados dessa forma correspondem aos enunciados existenciais da lógica de $1^{\text {a }}$ ordem. Os enunciados existenciais da forma "S existe" (onde "S" significa um indivíduo) afirmam a existência atual do indivíduo mencionado pelo sujeito e classificam o que é mencionado pelo sujeito como um ente categorial. Ver: GEACH. Three philosophers, p. 88-91. Ver também: WEIDEMANN, 2002, p. 77-95.

2 "(...) que também pode ser dita [composição] do que é (quod est) e ser (esse) ou do que é (quod est) e daquilo pelo qual algo é (quod est)" (Summa contra gentiles, II, 54, grifos no original).

3 Peryermenias, op. cit., I, cap. 2, p. 11.

4 Librum boethii de trinitate, q. 6, a. 2.

5 Ver, por exemplo, os comentários ao De trinitate (op. cit., q. 5, a. 3), ao Peryermenias (op. cit., I, 1, p. 5) e à Metafísica (in Libros metaphysicorum, 1, VI, cap. 4). 
e divisão ( $2^{\mathrm{a}}$ operação do intelecto). $\mathrm{O}$ inteligir os indivisíveis, habitualmente denominado pela tradição tomista de apreensão qüididativa, é condição da realização da $2^{a}$ operação de compor e dividir que, segundo certas condições, exprime formalmente a realização do ato cognitivo. Note-se que a $2^{\mathrm{a}}$ operação não é denominada juízo, pois, sob certo aspecto, os sentidos também julgam, embora só o intelecto julgue por composição e divisão. ${ }^{1}$

A análise dessa dupla operação será o fio condutor dessa parte do artigo.

A intelecção dos indivisíveis tem um duplo aspecto: ela consiste na intelecção do que é, qüididade (num sentido lato de qüididade ou de essência), ${ }^{2} \mathrm{e}$ na formação ou produção de conceitos através da apreensão do que é.

É por abstração ${ }^{3}$ que se intelige $o$ que é, seja por abstração do universal a partir do particular (abstração denominada por Tomás de abstração do todo ou de abstração não-precisiva da matéria signata), seja por abstração da forma (abstração precisiva). ${ }^{4}$ Pela primeira operação do intelecto, se apreende uma qüididade, uma determinação inteligível. A qüididade foi extraída da imagem sensível pela ação do intelecto agente graças a um processo abstrativo que deixa de lado as condições individualizantes do conteúdo apresentado pela imagem sensível. Ela é impressa no intelecto possível. Tomada nela mesma, isto é, considerada absolutamente sem relação com a imagem da qual foi abstraída ou com o indivíduo que a singulariza ou com o conceito que a exprime, ela não é nem una nem múltipla, nem universal nem singular, pois o seu modo de existência foi deixado de lado. Ela foi obtida por abstração não-precisiva da matéria signata. Tomás no De ente denomina a qüididade assim obtida de natureza absolutamente considerada. ${ }^{5}$

Assim, a essência ou qüididade pode também ser considerada por abstração dos seus modos de existência. De fato, a essência existe nas coisas singulares ou é expressa pelo conceito de modo universal na mente. Ela pode ser analisada como essência disto ou daquilo e, nesse caso, é considerada a essência de alguma coisa, possível ou atual. Pode também ser expressa por um

1 De veritate, q. 1, a. 9. (Ver tradução francesa, edição bilíngüe, de BROUWER e PEETERS, 2002)

2 Qüididade exprime a definição formal da essência. Ver: Summa theologiae (ST) I, 29, a. 3. Nós usaremos esse termo de uma maneira vaga significando apenas qualquer propriedade inteligível.

3 A operação de abstração foi analisada por Tomás tematicamente nos textos: Librum boethii de trinitate (op. cit., q. 5, a. 3), no De ente et essentia, cap. 2 e na Summa theologiae, I, q. 85, a. 1 e 2.

4 Note-se que a teoria da abstração tomásica foi modificada, ao menos do ponto de vista terminológico, por Cajetano nos seus Comentários ao De ente et essentia e à Summa. A abstração foi classificada então em abstração formal com os seus três graus (abstração da matéria sensível, da matéria inteligível e da matéria) e abstração total. Essas distinções de graus de abstração (e não de modos de abstração) não exprimem integralmente a concepção tomásica de abstração e, de toda maneira, põem indiretamente em questão a função do juízo que será exposta neste artigo.

5 De ente, op. cit., cap. 2, p. 91-95. Sobre a noção de natureza absolutamente considerada ver: a) CAJETANO, 1964, p. 155-164; b) EDWARDS, 2002, p. 97-115; c) OWENS, 1980, p. 52-96; d) TONQUÉDEC, 1961 , p. 155-163. 
conceito universal. Mas, caso seu modo de existência tenha sido deixado de lado, ela, nela mesma, não é nem singular nem universal.

A partir da qüididade apreendida, o intelecto forma ou produz conceitos que são entes intencionais que existem no intelecto de modo universal. Eles são expressos por definições, que explicitam por notas inteligíveis os diferentes aspectos da qüididade. Assim, o conceito, ou ao menos o conceito denominado pelos escolásticos de universal direto, exprime e contém de modo universal a qüididade apreendida. Como o universal é o que pode ser predicado de muitos ${ }^{1}$, o conceito qüididativo, em princípio, pode ser predicado de diferentes coisas singulares.

Tomás afirma que é a essência absolutamente considerada que é predicada dos indivíduos. ${ }^{2}$ Mas, já que o conteúdo de um conceito (universal direto) é uma mera determinação inteligível, uma essência absolutamente considerada, como é possível relacioná-la com coisas singulares? Por não ser nem una nem múltipla, nem singular nem universal, como a essência absolutamente considerada, expressa conceitualmente, poderia ser atribuída de maneira unívoca a entes numericamente distintos? Os enunciados Pedro é homem e João é homem são, em princípio, verdadeiros. Mas não é a essência singular de Pedro que é atribuída a Pedro, pois se o fosse, ela não poderia ser atribuída a João. É a essência absolutamente considerada que é atribuída de maneira unívoca a Pedro e a João e que, graças a essa atribuição, é considerada como instanciada em Pedro e em João. Mas, como pode ser atribuída a entes numericamente distintos, sem ser considerada universal, já que o universal é definido como o que pode ser dito de muitos? Mas, se for universal, como poderia "existir" individualizada em diferentes indivíduos? ${ }^{3}$

De fato, numa predicação afirmativa elementar, deve ser distinguido o que é atribuído à coisa mencionada pelo sujeito (a essência absolutamente considerada) das condições que permitem a atribuição (o fato de no intelecto a essência absolutamente considerada ter um modo de existência universal). ${ }^{4}$ Por existir no intelecto de modo universal, a essência absolutamente considerada pode ser atribuída a muitos indivíduos numericamente diferentes. O predicado "homem" nas predicações "Pedro é homem" e "João é homem" tem um sentido unívoco, pois o que está sendo atribuído a entes numericamente

1 De interpretatione, op. cit., 17³9-40. A. de Libera cita a distinção conceitual de Pedro de Espanha entre predicável e universal: predicável é o que está apto a ser dito de muitos, e universal, o que é apto a existir em muitos. (Ver: LIBERA, 1996, p. 234.)

2 De ente, op. cit., cap. 3, p. 93 : "Ergo patet quod natura hominis absolute considerata abstrahit a quolibet esse, ita tamen quod non fiat praecisio alicuius eorum. Et haec natura sic considerata est quae est praedicatur de individuis omnibus".

3 Ver sobre esse problema : De ente, op. cit., p. 91-94 e o livro de LIBERA, 1996, p. 281-282.

4 CAJETANO, 1964, p. 156. 
diferentes (Pedro e João) é a essência absolutamente considerada, que por fazer abstração das características individuais de Pedro e de João, pode ter a mesma relação de semelhança uniforme com Pedro e com João, que são indivíduos que na realidade têm uma essência numericamente distinta. Tomado nele mesmo, independentemente da sua ocorrência na predicação, o conceito homem não significa nem a essência individual de João nem a de Pedro. O seu significado independe do modo pelo qual o seu conteúdo existe no indivíduo ou na mente. Não só a universalidade do conceito que possibilita que a essência seja predicável de muitos indivíduos, como também a sua existência singular neste ou naquele indivíduo, são acidentais à própria essência enquanto ela é absolutamente considerada.

Mas como a essência absolutamente considerada que não significa qualquer essência individual pode ser a similitude da essência de um ente singular? Como um conceito universal, que exprime uma essência absolutamente considerada, pode representar uma coisa singular?

Essas questões repercutem na análise lingüística dos enunciados predicativos. Por razões epistêmicas e ontológicas, Tomás afirma que não é possível inteligir as coisas singulares, compostas de matéria e de forma, a não ser mediante conceitos. As coisas singulares materiais não são inteligíveis diretamente pelo intelecto em razão da matéria, que é o seu princípio da individuação, ser apenas potencialmente inteligível. Só indiretamente, mediante uma certa reflexão, o intelecto conhece as coisas singulares. ${ }^{1}$ É preciso abstrair, isto é, deixar de lado as condições individualizantes das coisas singulares materiais, para torná-las inteligíveis em ato. Em razão disso, o intelecto humano forma conceitos, que expressam naturezas absolutamente consideradas. Ora, como já assinalamos, numa oração predicativa, o sujeito lógico tem a função de mencionar coisas. As expressões que exercem a função de sujeito lógico numa oração predicativa são termos gerais, que significam conceitos, pois se não significassem conceitos, as coisas singulares, em princípio não seriam inteligidas, não podendo, em conseqüência, ser mencionadas. Uma pergunta, então, se impõe: Como termos gerais, que significam conceitos universais, podem mencionar coisas singulares, se conceitos exprimem essências absolutamente consideradas, portanto, qüididades sem qualquer relação com coisas singulares? Como os termos gerais significando conceitos podem mencionar coisas singulares?

A semântica de Tomás classifica ${ }^{2}$ as orações predicativas elementares (unas e simples ${ }^{3}$, segundo o vocabulário tomásico) do ponto de vista da sua 
qualidade (afirmativas/negativas) e do ponto de vista da sua quantidade (universais/particulares/singulares/indefinidas). Uma oração predicativa é universal, se o seu conceito-sujeito é tomado universalmente. Note-se que o conceito é sempre universal. Quantificá-lo significa tomar o universal (conceito) universal, particular ou singularmente. Uma oração predicativa é particular (singular), se o seu conceito-sujeito é tomado particularmente (singularmente). Uma oração predicativa é indefinida, se o seu conceito-sujeito não é precedido pelos sincategoremas "todo", "algum", "este". Nesse caso, ela é assimilada a uma oração particular. Assim, quantificar uma oração significa quantificar o conceito-sujeito $^{1}$ da oração predicativa. Mas, qual é o sujeito lógico dessas orações quantificadas, se o seu conceito-sujeito é sempre um universal que pode ser tomado universal, particular ou singularmente?

Do ponto de vista tomásico, não seria equivocado afirmar que os sujeitos lógicos (aquilo sobre o que versa a oração predicativa elementar) ${ }^{2}$ são sempre os indivíduos singulares ora considerados enquanto singulares ora considerados enquanto o que é comum a vários indivíduos singulares. De fato, no seu Comentário ao De interpretatione de Aristóteles, Tomás explica que se pode considerar numa coisa singular o que lhe é próprio (que, portanto, pertence somente a essa coisa singular) e também o que é comum a diversas outras coisas singulares. Pode-se atribuir a Sócrates o que pertence somente a Sócrates, como também se pode atribuir a Sócrates o que é comum a Sócrates, a Platão e a outros indivíduos.

Tomás, comentando Aristóteles, explica o sentido dos quantificadores da seguinte maneira. Pode-se predicar algo do universal de duas maneiras: a) como tendo uma existência separada dos singulares (uma existência na mente, por exemplo) ou b) como estando nos singulares. Isso explicaria a diferença entre os seguintes tipos de enunciado: Homem é uma espécie e $O$ homem é mortal". O caso "a" foi analisado exaustivamente pela teoria medieval da suposição que diferenciou diversos tipos de suposição, o que, entre outras coisas, permitiu distinguir enunciados do tipo homem tem 5 letras dos enunciados do tipo homem é uma espécie. Mas, para Tomás, a quantificação aplica-se somente ao caso "b". Como já assinalamos, o (conceito) universal pode ser tomado

1 Certos lógicos medievais aceitavam que o predicado também pudesse ser "quantificado": o predicado de uma oração predicativa afirmativa seria tomado particularmente; o predicado de uma oração predicativa negativa seria tomado universalmente.

2 Obviamente, essa análise se aplica às orações predicativas cujos termos gerais significam o universal direto.

3 Assinale-se que não existe artigo definido em latim. 
universal, particular ou singularmente. O que significaria, por exemplo, tomar o universal universalmente? Tomás explica:

Com efeito, algumas vezes se atribui alguma coisa a um universal [a um conceito universal] em razão de sua natureza universal; diz-se, então, que algo é predicado universalmente dum universal, pois este universal convém a todos os singulares nos quais ele se encontra; também para significá-lo nas predicações afirmativas forjou-se a expressão "todo" que designa um predicado atribuído a um sujeito universal para todas aquelas coisas que estão contidas sob esse sujeito. ${ }^{1}$

O conceito universal (obtido por abstração não-precisiva), que é sujeito de uma oração predicativa, pode significar uma única coisa. Nesse caso, o conceito universal é tomado singularmente. Daí as orações da forma: Este homem (seja Sócrates) é X. Mas o conceito universal pode significar também o que é comum a todas ou a algumas coisas singulares. Daí as orações da forma: Todo homem (isto é, Sócrates e Platão e Aristóteles e ...) é Xe Algum homem (Sócrates ou Platão ou ...) é X. Nesse caso, o conceito universal é tomado universal ou particularmente significando uma propriedade comum a diferentes indivíduos. Daí se segue que o sujeito lógico não é a propriedade comum expressa pelo conceito, mas são os indivíduos que têm em comum a propriedade significada pelo conceito.

Explicar dessa maneira a função dos quantificadores pressupõe que os conceitos universais (obtidos por abstração não-precisiva) tomados universal, particular ou singularmente tenham uma relação com as coisas singulares. Assim, o conceito universal significaria singulares sob uma propriedade comum. Como justificar essa tese, uma vez que os conceitos têm como conteúdo essências absolutamente consideradas?

A $1^{a}$ operação do intelecto envolve uma relação com o sensível pelo fato de a qüididade ter sido abstraída da imagem sensível. Mas envolve também uma outra relação com o sensível em razão da operação denominada por Tomás de "retorno à imagem sensível"2. A justificação da necessidade dessa operação é complexa, pois envolve considerações epistêmicas e ontológicas. Como já assinalamos, é tese tomásica que o intelecto apreende diretamente apenas o universal, só indiretamente o singular, pois este só seria captado pelos sentidos ${ }^{3}$. Assim, se o conhecimento humano tivesse como objeto próprio apenas a qüididade expressa conceitualmente, poderiam ser conhecidas pelo intelecto humano apenas as formas separadas da matéria, representadas pelas

1 Peryermenias, op. cit., I, cap. 10, p. 52.

2 Summa theologiae, I, 84, a. 7.

3 Summa theologiae, I, 86, a. 1. Note-se que o intelecto apreende diretamente, mas não imediatamente, o universal, já que o universal é obtido pela operação de abstração. 
determinações inteligíveis abstratas. Mas, segundo a tese hilemórfica, pertence à natureza dessas formas existirem num indivíduo composto de matéria e de forma. É da razão da natureza da pedra existir nessa pedra ${ }^{1}$. Portanto, se o intelecto humano tiver o poder de conhecer, o objeto próprio de seu conhecimento não pode ser a qüididade que é expressa conceitualmente, mas deve ser a qüididade nas coisas materiais ${ }^{2}$. A qüididade abstrata é sempre para Tomás indeterminada; o determinado é sempre o singular concreto ${ }^{3}$. E este só pode ser "representado ou conhecido pelo "retorno à imagem sensível"".

É, portanto, necessário concretizar a qüididade ou fazer, segundo a expressão de Maréchal, uma síntese concretiva, isto é, correlacionar a qüididade abstrata com a imagem sensível que, tomada nela mesma, é uma representação subjetiva de um conteúdo singular. Essa síntese concretiva torna inteligível a imagem e mostra como o conceito universal pode ser considerado como uma representação (similitude) inteligível de objetos singulares.

Mas a síntese concretiva é ainda uma operação que pertence à $1^{\mathrm{a}}$ operação do intelecto. Ela não é uma síntese judicativa entre o predicado e o sujeito, é apenas uma condição para que seja efetuada uma predicação. De fato, as orações predicativas afirmativas elementares têm a forma $S$ é $P$, onde "S" está no lugar de um termo geral, quantificado ou não. Os sujeitos das orações predicativas são sempre termos gerais que significam conceitos universais. A relação conceito-imagem é uma condição para que um conceito possa mencionar ou representar objetos singulares num juízo por composição e possa, dessa maneira, exercer a função de sujeito da oração predicativa.

Assim, a síntese concretiva permite explicar que sob uma propriedade comum, expressa conceitualmente, estão contidas representações sensíveis de objetos singulares. Isso tornaria uma série de definições ou de teses tomásicas plausíveis: a definição do universal como o que pode ser dito de muitos; a tese de que o sujeito lógico das orações predicativas elementares com termos gerais quantificados seria as coisas singulares etc.

\section{Predicação, composição e divisão}

A $1^{\text {a }}$ operação da mente concerne à representação conceitual de objetos; a $2^{\mathrm{a}}$ operação, ao conhecimento de objetos. Habitualmente, a $2^{\mathrm{a}}$ operação do intelecto é denominada pelos intérpretes tomistas de operação judicativa ou de

1 "(...) sicut de ratione naturae lapidis est quod sit in hoc lapide, et de ratione naturae equi quod sit in hoc equo, et sic de aliis" (Summa theologiae, I, 84, a. 7, c).

2 Summa theologiae, I, 85, a. 8 ; I, 88, a. 2 e 3.

3 Ver FOREST, 1956, p. 72-97. 
juízo. No entanto, de certa maneira, como já assinalamos, os sentidos também julgam. ${ }^{1}$ De fato, Tomás denomina essa $2^{\mathrm{a}}$ operação de composição e divisão. Assim, é útil distinguir o juízo, que pode ser um ato dos sentidos ou do intelecto, do ato propriamente intelectual que consiste em julgar por composição e divisão que caracteriza a $2^{\mathrm{a}}$ operação. $\mathrm{O}$ intelecto humano conhece judicativamente mediante composição ou divisão. ${ }^{2}$

A composição de que trata a $2^{\mathrm{a}}$ operação do intelecto não é, no entanto, uma mera união de conceitos, como seria a que uniria dois conceitos distintos; por exemplo, a que seria expressa pelo conceito complexo homem justo. Compor e dividir significam sintetizar conceitos por modo de predicação. Tomás explica de maneira precisa o significado de uma composição conceitual por predicação: "Em toda proposição, uma forma significada pelo predicado ou se aplica a alguma coisa significada pelo sujeito ou então é da coisa removida". ${ }^{3}$ Numa oração predicativa afirmativa, mediante o conceito-sujeito, é expressa uma propriedade sob a qual podem cair diversas coisas (objetos) que têm em comum essa propriedade. Mediante o conceito-predicado é expressa uma propriedade que se aplica às coisas mencionadas pelo conceito-sujeito. Graças ao conceito-sujeito, o conceito-predicado (que significa uma forma ${ }^{4}$ ) é relacionado com as coisas mencionadas pelo sujeito da oração predicativa. Assim, vê-se que a oração predicativa não pode ser analisada como se fosse uma relação entre duas coisas significadas pelo conceito-sujeito e pelo conceito-predicado. Ela é analisada por Tomás de maneira análoga à relação da forma com a matéria: o predicado significa uma forma que determina inteligivelmente a coisa significada pelo sujeito que, dessa maneira, exerce a função de matéria na composição hilemórfica. "Os predicados são assumidos formalmente e o sujeito materialmente." 5

A composição ou divisão predicativa é caracterizada pela distinção de duas funções, ambas exercidas por conceitos: o conceito-sujeito menciona coisas (uma determinada coisa ou algumas coisas ou todas as coisas que têm

1 Ver, por exemplo, De veritate, op. cit., I, 9 e Summa theologiae, I, 17, a. 2.

2 "(...) mas quando julga que a coisa é da maneira que é a forma que apreende da coisa; então primeiramente conhece e diz a verdade. E faz isso compondo e dividindo; pois em toda proposição alguma forma significada pelo predicado ou é aplicada a alguma coisa significada pelo sujeito ou é removida dele" (Summa theologiae, I, 16, a. 2, c; grifo nosso).

3 Idem.

4 Ver ANSCOMBE e GEACH, 1961, p. 75-81. Segundo esses autores, o que Tomás denomina de forma pode ser expresso como um predicado lógico... é $P$ ou (no caso de a forma ocupar a posição de sujeito da predicação) pode ser significado pela expressão $P$ de..., exigindo, assim, um complemento de um nome (próprio) de objeto. Mas a semântica tomásica terá a noção de nome próprio? Nome próprio não seria uma descrição definida disfarçada?

5 Summa theologiae, I, 13, a. 12, c. e Peryermenias, op. cit., I, cap. 8, p. 42: “(...) pois o predicado é relacionado ao seu sujeito como a forma à matéria". 
em comum uma propriedade) e o predicado só classifica ou determina inteligivelmente as coisas pela mediação do conceito-sujeito. Daí se compreende a tese do lógico tomista Vincent Ferrer ${ }^{1}$ que afirmava que os predicados não supõem, pois não mencionam diretamente as coisas; só o conceito-sujeito na predicação pode fazer suposição de existência; os predicados apenas classificam, mediante propriedades, as coisas mencionadas pelo conceito-sujeito.

Qual é a operação lingüística que significa a operação de composição e divisão?

Tomás de Aquino distinguiu no Peryermeneias ${ }^{2}$ as orações denominadas de orações perfeitas (como as orações interrogativas, imperativas, deprecativas etc.), que se caracterizam por serem orações que não têm valor de verdade, das orações perfeitas que têm valor de verdade e que são denominadas de enunciados. Assim, enunciados seriam orações cujo gênero seriam as orações perfeitas. As orações que Tomás denomina de orações perfeitas são as que denominamos de orações predicativas. Estas se caracterizariam pela aplicação ou exclusão de uma propriedade à coisa significada pelo sujeito. Dessa maneira, fica determinado o que está sendo atribuído ao que está sendo mencionado. Assim, por exemplo, por satisfazer as condições da predicação, uma oração interrogativa seria uma oração predicativa, mas não seria um enunciado, pois interrogações não são nem verdadeiras nem falsas.

Uma conseqüência dessa distinção é a de que as orações predicativas, embora nelas o predicado esteja unido ao sujeito pela cópula, não envolvem uma descrição do real, pois não dizem ou afirmam que algo é ou não é o caso. No entanto, a síntese do predicado com o sujeito na predicação se realiza mediante o verbo ser. Qual é o significado desse verbo nas orações predicativas? Ao lado de sua função de síntese, ele não teria também uma função existencial? Ele não significaria (ou co-significaria, segundo a expressão de Tomás) que algo seria o caso? Nesse caso, as orações predicativas não teriam, nelas mesmas, uma função apofântica? Em conseqüência, elas não deveriam ser assimiladas a enunciados?

Ao lado da distinção entre as orações perfeitas que têm e as que não têm valor de verdade, Tomás introduziu também uma outra distinção que se aplica às orações predicativas e, conseqüentemente, aos enunciados. Trata-se da diferença entre orações predicativas de segundo e de terceiro adjacente. Essa distinção esclarece a função desempenhada pelo verbo ser e diferencia a função atributiva da função existencial dos enunciados.

2 Peryermeneias, op. cit., I, cap. 7. 
Uma oração de terceiro adjacente é composta de um termo-sujeito e de um predicado formado por duas palavras: o verbo ser e uma outra expressão (termo-nome que significa um conceito). A forma desse enunciado é $S$ é $P$, onde $\boldsymbol{e} \boldsymbol{P}$ é uma expressão complexa, formada por dois termos, sendo que um deles é um nome.

(...) é é predicado como adjacente ao principal predicado. E diz-se que é terceiro, não porque seja um terceiro predicado, mas porque é uma terceira expressão colocada no enunciado que, simultaneamente, com um nome-predicado forma um único predicado, de tal maneira que o enunciado é divido em duas e não em três partes ${ }^{1}$ (grifos nossos).

Assim, o verbo ser, enquanto exerce a função de cópula, tem o sentido do verbo inesse: a forma significada pelo sujeito está (ou não) na coisa significada pelo sujeito. $^{2}$

Uma oração de segundo adjacente é formada por dois termos: termo-sujeito e um termo simples, que é um verbo, pois não há oração predicativa sem verbo. ${ }^{3}$ Se o verbo da oração de segundo adjacente é o verbo ser, a oração predicativa significa que o que é significado pelo termo-sujeito existe. Note-se que essa predicação "existencial" poderia ser usada numa pergunta, numa prece, poderia ser usada, portanto, sem função apofântica.

Quando aplicada aos enunciados, a distinção entre orações de segundo adjacente e de terceiro adjacente permite diferenciar lingüisticamente a função existencial da função atributiva dessas orações. O enunciado de segundo adjacente da forma $S$ é é um enunciado existencial e significa que existe o objeto mencionado pelo sujeito: “(...) quando se diz que Sócrates é (existe): através disso nada de outro pretendemos significar senão que Sócrates existe na natureza (sit in rerum natura)". ${ }^{4}$ Mas, num enunciado de terceiro adjacente (da forma $S$ é $P$ ), não é afirmada diretamente a existência efetiva do que é expresso pelo termo-sujeito, mas é dito que a coisa indicada pelo sujeito satisfaz à propriedade significada pelo predicado. Assim, num enunciado de terceiro adjacente, a existência da coisa mencionada não é afirmada, embora possa ser suposta. Obviamente, supor a existência de uma coisa não equivale afirmar sua existência.

1 Peryermenias, op. cit., II, cap. 2, p. 88.

2 Libros metaphysicorum, 1, VI, cap. 4, n. 1223: "Assim, aqui afirmação é denominada (dicitur) composição porque ela significa que o predicado está (inesse) no sujeito. Mas a negação é denominada (dicitur) divisão, porque ela significa que o predicado foi removido do sujeito".

3 Peryermenias, op. cit., I, cap. 8, p. 40-41.

4 Ibidem, II, cap. 2, p. 88. 
Mas, algumas vezes é não é predicado por si, como predicado principal, mas como unido ao predicado principal para conectá-lo ao sujeito, assim como quando se diz Sócrates é branco. Não é intenção do locutor afirmar que Sócrates existe na nature$\mathrm{za}$, mas de atribuir a ele a brancura mediante este verbo é (grifos no original). ${ }^{1}$

Dessa maneira, Tomás parece rejeitar a análise do enunciado predicativo da forma $S$ é $P$ como significando $S$ existe enquanto $P^{2}$, pois nos enunciados de terceiro adjacente, a existência não é posta, mas é apenas suposta. Isso mostra, que a forma predicativa ou categórica do enunciado não é suficiente para determinar o gênero de suposição de existência que deve ser feito para que o enunciado seja verdadeiro. Assim, por exemplo, enunciados predicativos elementares negativos, ao contrário dos enunciados predicativos afirmativos, podem ser verdadeiros mesmo que não existam as coisas mencionadas pelo termo-sujeito.

\section{Enunciado e juízo por composição e divisão}

Tomás de Aquino afirma que, dentre as orações predicativas, só os enunciados têm valor de verdade. Daí se segue que só os termos complexos da $2^{\mathrm{a}}$ operação do intelecto, isto é, os juízos por composição e divisão, podem ter valor de verdade. Termos incomplexos, os conceitos, não seriam nem verdadeiros nem falsos. No entanto, certos textos de Tomás contrariam essa tese, pois dizem que as faculdades cognoscitivas não podem errar e são sempre verdadeiras em relação aos seus objetos próprios. Há, portanto, verdade nas operações dos sentidos e na $1^{\mathrm{a}}$ operação do intelecto ${ }^{3}$. Ora, como o objeto próprio da faculdade intelectiva é a qüididade das coisas materiais, só acidentalmente o intelecto se enganaria nas definições que explicitam as características das qüididades.

Haveria uma inconsistência nas afirmações de Tomás de Aquino: de um lado só os termos complexos por composição e divisão seriam verdadeiros ou falsos. Por outro lado, os sentidos e o intelecto (enquanto apreende as qüididades das coisas materiais) são verdadeiros em relação aos seus objetos próprios. Portanto, o que resulta das operações que precedem o ato judicativo por composição e divisão seria verdadeiro. Como, então, compatibilizar as afirmações tomásicas: de um lado só há verdade no juízo por composição e divisão, por outro lado, o termo de algumas das operações pré-judicativas pode ser considerado verdadeiro? 
O esclarecimento dessa questão nos remete à análise da noção de verdade. Tomás de Aquino analisa a verdade sob três aspectos $\left.{ }^{1}: 1\right)$ o fundamento da verdade (o ente), aquilo que torna um enunciado verdadeiro, 2) a definição formal da verdade, que é a conformidade do intelecto à coisa e 3) a conseqüência da verdade, que é o conhecimento.

Os dois primeiros aspectos não são problemáticos quando formulados num contexto realista. Se a verdade é definida formalmente como conformidade do intelecto à coisa, é a coisa real que torna o enunciado verdadeiro, “(...) assim, a entidade da coisa precede a razão da verdade, mas a cognição é certamente o efeito da verdade". ${ }^{2}$ Qual o significado preciso desse terceiro aspecto da análise da verdade?

Tomás parece ter sido levado a formular essa tese em razão dos seguintes argumentos: as species sensíveis ${ }^{3}$, e, particularmente, a species sensível da imaginação ${ }^{4}$, são representações (similitudes) das coisas sentidas. Os conceitos qüididativos são também similitudes de propriedades de coisas. Em relação

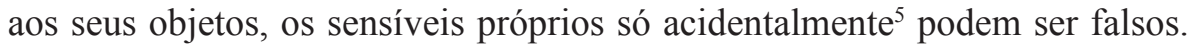
Tal ocorre também em relação aos conceitos na medida em que a qüididade das coisas materiais é o objeto próprio do intelecto humano e que conceitos significam qüididades 6 . Pode-se, então, afirmar que, sob esse aspecto, "descobre-se que os sentidos são verdadeiros de alguma coisa ou que o intelecto também o é quando conhece aquilo que é. Mas não que conheça ou diga a verdade". ${ }^{7}$ Assim, se os objetos próprios dos sentidos e as qüididades, expressas pelos conceitos, podem ser considerados verdadeiros, segundo Tomás, as faculdades que apreendem esses objetos não conhecem nem dizem a verdade ${ }^{8}$ (grifos no original). Só o intelecto no juízo por composição e divisão pode conhecer sua conformidade à coisa conhecida, isto é, só no juízo a verdade é conhecida. ${ }^{9}$ Por quê?

Os atos mentais das faculdades cognoscitivas envolvem reflexão. ${ }^{10} \mathrm{Re}-$ fletir é a consciência (cognitio) que se tem do exercício de um ato mental, ${ }^{11}$ é

1 De veritate, op. cit., I, 1.

2 Idem. Ver também: Summa theologiae, I, 16, a. 2, c.

3 Summa theologiae, I, 17, a. 2; I, 78, a. 4, ad 2.

4 Summa theologiae, I, 79, a. 4, ad 4.

5 De veritate, op. cit., I, a. 11; Summa theologiae, I, 17, a. 2.

6 Summa theologiae, I, 17, a. 3; I, 85, a. 6.

7 Summa theologiae, I, 16, a. 2, c. (grifos no original)

8 Summa theologiae, I, 16, a. 3, c. Ver também Libros metaphysicorum, I, VI, cap. 4 e Peryermenias, op. cit., I, cap. 3, p. 16-17.

9 "Daí conhecer esta conformidade é conhecer a verdade" (Summa theologiae, I, 16, a. 2, c).

10 De veritate, op. cit., q. 1, a. 9. Ver o comentário clássico desse artigo por BOYER, 1924, p. 219-224 e o livro de DE FINANCE, 1946, p. 23- 46 e o de PUTALAZZ, 1991, p. 150-202.

11 Os atos sensíveis têm também uma certa reflexão: "Porém os sentidos... conhecem o sensível, mas também conhecem que sentem..." (De veritate, op. cit., I, 9). 
conhecer que se conhece; é, portanto, a consciência do ato exercido. O ato de predicar, enquanto ato do intelecto, envolve reflexão. Mas a reflexão envolvida no ato de predicar é a consciência da relação (proportio) da atribuição da forma intencional significada pelo predicado à coisa significada pelo sujeito; é, portanto, consciência da relação da atribuição da forma (expressa pela species inteligível) ao objeto/coisa. Portanto, o ato de predicar é um ato exercido com consciência e, nesse caso, a consciência é a consciência da relação da representação intencional, expressa pelo predicado, ao objeto significado pelo sujeito. Nesse caso, a consciência não é algo que se superpõe ao ato, mas algo que constitui (e não apenas acompanha) o ato de predicar, isto é, o ato de predicar depende da consciência do ato porque é por ela constituído. Por quê?

$\mathrm{O}$ ato de predicar tem o intelecto como seu princípio. Em razão disso, a consciência do ato de predicar envolve a consciência desse princípio. A consciência desse princípio é a consciência da finalidade (ou função) do intelecto. Tomás exprime a consciência dessa "função" como sendo a consciência da "natureza" do intelecto. Não se trata, no entanto, da consciência qüididativa da essência do intelecto na medida em que o intelecto é uma faculdade imaterial, independente do corpo, que tem a alma humana como seu sujeito, pois, em caso contrário, só os filósofos metafísicos poderiam predicar. Trata-se, nesse caso, da consciência de que a finalidade do intelecto é a de visar às coisas ou "a de se conformar às coisas". $\mathrm{O}$ intelecto seria, então, uma faculdade que se caracterizaria por um dinamismo intrínseco, o de visar às coisas².

Assim, segundo o texto do De veritate, a atribuição de uma propriedade, expressa pelo predicado, a uma coisa, mencionada pelo sujeito, tem por condição: a) a consciência (cognitio) da relação (proportio) do ato à coisa, b) que, por sua vez, tem como condição a consciência de que o intelecto é o princípio do ato de predicar e c) que finalmente tem como condição a consciência da "natureza" do intelecto, isto é, a consciência de sua função ou de seu dinamismo, que é o de se conformar às coisas. A reflexão (consciência ou cognição) que constitui o ato de predicar e que envolve a consciência da "natureza" do intelecto é denominada de reflexão completa.

Ter uma species inteligível, como ocorre, por exemplo, quando se apreende uma qüididade, pode envolver consciência na medida em que o ato de

1 Essa tese é apenas postulada no De veritate, mas foi longamente tematizada por Maréchal no que ele denominou, no seu livro, de Crítica Metafísica do Objeto. Ver Le point de départ de la métaphysique, op. cit., p. 49-51.

2 Ver PUTALLAZ, 1991, p. 195: “(...) conhecer a natureza do intelecto não significa exatamente 'conhecer sua essência'; conhecer a natureza do intelecto significa apreender (saisir) o princípio do dinamismo intelectual que conduz o intelecto a se conformar às coisas, por natureza, ao que é". A noção de dinamismo intelectual é central à interpretação marechaliana da epistemologia tomásica. Graças a ela, seria possível, segundo Maréchal, superar o formalismo da interpretação kantiana do juízo. 
formar um conceito qüididativo é um ato intelectual; mas a consciência desse ato não envolve a consciência da relação de atribuição entre a forma e a coisa, pois é essa relação que caracteriza o ato de predicar e o distingue do ato de formar conceitos. Não envolvendo essa consciência da relação, não pode envolver a consciência do dinamismo do intelecto, que é o de se conformar às coisas. Segue-se que o ato de produzir conceitos não envolve uma reflexão completa. ${ }^{1}$

Já assinalamos que "orações predicativas" significam composição e divisão pressuposta por todo juízo intelectual; "enunciados" significam juízos por composição e divisão, que se caracterizam por terem valor de verdade. Mas se "predicar" significa compor ou dividir e se a noção de juízo por composição e divisão não é assimilada à noção de predicação, é legítimo perguntar se as condições acima indicadas são condições necessárias e suficientes para a realização do ato predicativo (ou do ato de composição e divisão) ou se são condições necessárias e suficientes para a realização do ato judicativo por composição e divisão.

O texto do De veritate concerne o conhecimento da verdade, isto é, o conhecimento da conformidade do juízo com a coisa, que só o juízo por composição e divisão (e não a mera predicação) é capaz de exprimir. Mas, se é assim, a mera predicação (ou composição e divisão) não contém uma condição que só o juízo por composição e divisão pode conter e que o torna suscetível de ser efetivamente verdadeiro ou falso. Qual seria essa condição?

No Comentário à metafisica, Tomás escreve: "Com efeito, os termos simples não significam nem a verdade nem a falsidade. Mas os termos complexos têm verdade ou falsidade através da afirmação e da negação"2 (grifo nosso).

Qual o significado das expressões afirmação e negação?

Comentando um texto do De interpretatione $e^{3}$ de Aristóteles e algumas de suas interpretações medievais, Tomás assume a análise de Amônio e afirma: “(...) ele [Ammonius] acrescenta (subdit) que a afirmação é a enunciação de

1 Essa afirmação significa que o dinamismo intelectual só se exprime conscientemente no juízo por composição e divisão. No seu comentário à metafísica (Libros metaphysicorum, I, VI, cap. 4, n. 1236), Tomás resume o seu argumento da seguinte maneira: "Porém o intelecto tem em si a similitude das coisas inteligidas quando concebe as razões dos incomplexos. Mas, em razão disso ele não julga a própria similitude, mas só faz isso quando compõe e divide. Com efeito, quando o intelecto concebe o que é animal, mortal, racional, ele tem em si a similitude de homem, mas ele não conhece por causa disso que ele tem essa similitude porque não julga que 'homem é um animal racional mortal'. Daí somente nessa segunda operação do intelecto [composição e divisão] está a verdade ou a falsidade segundo que o intelecto não somente tem a similitude da coisa inteligida, mas também reflete [reflectitur] sobre ela [similitude] a conhecendo e a julgando".

2 Libros metaphysicorum, 1, VI, cap. 4, n. 1223.

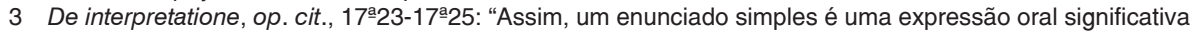
sobre aquilo que é algo ou não é (de eo quod est aliquid vel non est), segundo as divisões do tempo. Mas a afirmação é a enunciação de algo sobre algo e a negação é a enunciação de algo separado de algo". 
algo sobre algo pela qual é significado o ser e a negação é a enunciação de algo separado de algo, o que significa o não-ser" (grifos no original). ${ }^{1}$

Qual o sentido desse texto?

Habitualmente, uma predicação é denominada afirmativa se a função da cópula é a de compor o predicado com o sujeito. Para realizar essa função, é usado o verbo ser. A predicação é denominada negativa se a função da cópula é a de dividir ou a de separar o predicado do sujeito. Obviamente, essa função é realizada quando a cópula é precedida pelo operador "não". Mas a afirmação referida pelo texto de Tomás não é uma afirmação ou negação predicativa, é uma afirmação ou negação apofântica, pois a sua função não é apenas a de compor ou separar o predicado do sujeito, mas é, através dessa composição ou divisão, pôr como real a composição ou separação; é, assim, afirmar (ou negar) que algo é ou não o caso.

A afirmação e a negação apofânticas são operadores que exercem suas funções através da afirmação ou da negação predicativa, transformando a predicação afirmativa num enunciado afirmativo ou transformando uma predicação negativa num enunciado negativo. Enunciar uma predicação afirmativa significa considerar que a propriedade expressa pelo predicado está efetivamente na coisa mencionada pelo conceito-sujeito; enunciar uma predicação negativa significa, por sua vez, excluir uma propriedade (expressa pelo conceito-predicado) de algo efetivamente real ou significa considerar nãoexistente a coisa mencionada pelo conceito-sujeito. Por isso, ao afirmar ou ao negar uma predicação, é significado o ser ou o não-ser. Mas, significar o ser ou o não-ser através de uma composição ou divisão não é algo que a predicação faça por si mesma, mas é algo que o enunciado faz graças à afirmação ou à negação apofântica. Assim, afirmação e negação são operadores apofânticos e predicativos, pois, de um lado, transformam uma predicação numa enunciação, pondo a predicação como real (objetiva); por outro lado, são também operadores predicativos que exprimem ou bem a união ou bem a separação do predicado com o sujeito.

Tendo em vista a definição formal da verdade (concordância do intelecto com a coisa) e a função dos enunciados afirmativos ou negativos, é possível analisar suas condições de verdade. Surge, então, uma questão preliminar que despertou um certo interesse na semântica medieval: Qual a relação da negação com o valor de verdade falso? O falso, assim como a negação, significa o não-ser? 
Tomás distingue claramente na Suma teológica ${ }^{1}$ os sentidos das noções de negação, de privação e do valor de verdade falso. A negação não põe algo como efetivamente real [non ponit aliquid], pois não põe o predicado como pertencendo a um sujeito ou não "supõe" o sujeito como existente. A privação põe o sujeito como existente, mas não atribui ao sujeito algo de efetivamente real [non ponit aliquid]. É o que ocorre, por exemplo, com o enunciado a cegueira existe, que significa há algo que é cego. Esse enunciado "põe" a existência do sujeito, embora a pretensa "propriedade" (cegueira), atribuída ao sujeito, não seja, nela mesma, um ente, algo de efetivamente real, mas apenas a privação de uma propriedade ou de uma faculdade. O falso, assim como o verdadeiro, tem como "norma" o real (o ente) e, sob esse aspecto, ele "supõe" algo de real, falsum autem aliquid ponit. Mas, ao contrário do verdadeiro, o falso exprime uma concepção inadequada da realidade.

Num célebre texto do Peryermenias ${ }^{2}$ onde é formulada a conhecida tese da bipolaridade do enunciado que caracteriza a interpretação realista da verdade, Tomás pretende, de um lado, evitar qualquer ambigüidade na interpretação da negação, por outro lado, pretende mostrar que enunciados afirmativos e negativos, quando mencionam as mesmas coisas e atribuem a elas as mesmas propriedades, estão numa relação de oposição contraditória. Para evitar ambigüidades sobre a interpretação da negação, ao invés de definir o valor de verdade do enunciado negativo em função do valor de verdade do enunciado afirmativo, Tomás mostra que as condições de verdade desses enunciados devem ser formuladas de maneira independente, pois cada um deles, além de exprimir a afirmação ou negação predicativa, correlaciona, a seu modo, o que é significado pela oração predicativa com a realidade. Assim, por exemplo, um enunciado afirmativo é verdadeiro se enuncia que é $\boldsymbol{o}$ que é; _um enunciado negativo é falso se enuncia que não é_o que é; um enunciado afirmativo é falso se enuncia que é o que não é, um enunciado negativo é verdadeiro se enuncia que não é o que não é. Fixadas as condições de verdade dos enunciados afirmativos e negativos, fica evidenciada não só a função apofântica e predicativa deles, como também a relação de oposição contraditória entre eles.

Mas a afirmação de que um enunciado negativo verdadeiro significa que não é o que não é compromete a ontologia de Tomás de Aquino com o que foi denominado de fatos negativos? O que não é, o não-ser, seria o que tornaria verdadeiro o enunciado negativo?

Através do enunciado negativo verdadeiro não é significado que o que foi separado pela predicação corresponde ao não-ser, como se o não-ser fosse

2 De interpretatione, op. cit., 17 26 -29; Peryermenias, op. cit., I, 9, p. 47. 
uma realidade tal como é o ser, mas é significado que na realidade não se encontra a composição da propriedade (expressa pelo predicado) com a coisa (mencionada pelo sujeito) ou que a própria coisa, mencionada pelo sujeito, inexiste Por isso, graças à negação, pode-se "dizer o não-ser" sem se comprometer com uma ontologia de fatos negativos.

\section{Conclusão}

São conhecidas as disputas entre intérpretes tomistas do passado e do presente sobre o papel que as noções de essência (ou qüididade), ente, ser e existência desempenham na metafísica tomásica. Essas noções apareceram na exposição da teoria judicativa tomásica quando foram analisadas as noções de conceito, de juízo por composição e divisão e de enunciado existencial de segundo adjacente. As diferentes funções que essas noções exercem na teoria do juízo são indícios de certas teses da metafísica tomásicas que afirmam, por exemplo, a distinção ou composição real entre ser e essência no ente finito.

Conceitos conectados às imagens são representações (similitudes) do que são as coisas singulares. Exprimem de modo universal qüididades que, tomadas nelas mesmas, não são nem singulares nem universais, embora existam de modo singular nas coisas materiais e de modo universal/abstrato no intelecto ${ }^{1}$.

A formação de conceitos é uma etapa da produção de juízos. Conceitos exercem no juízo o papel de sujeito e de predicado permitindo que "algo seja dito de algo". Mas a predicação não é ainda uma instanciação de qüididades num sujeito singular existente. Tomás escreve no De ente et essentia ${ }^{2}$ : “(...) toda essência ou qüididade pode ser pensada sem que nada seja pensado do seu ser: posso com efeito inteligir o que [quid est] é homem ou o que é fênix e contudo ignorar se existe um tal ser na natureza; é claro que o ser é outra coisa que a essência ou qüididade”. Esse argumento parece se apoiar na diferença entre conceito e juízo e demonstra a distinção lógica (que não é ainda uma distinção real) entre essência e ser.

Todos os enunciados afirmativos ou negativos, verdadeiros ou falsos, significam o ser ou o não-ser, pois correlacionam a qüididade, expressa conceitualmente, com o real. Na teoria do juízo, a noção de ser ainda não tem o seu significado metafísico de "ato de todos os atos, perfeição de todas as

1 "Portanto, a própria natureza que ocorre ser inteligida ou abstraída ou a intenção de universalidade não existe senão nos singulares, mas isso mesmo que é inteligido ou abstraído ou a intenção de universalidade está no intelecto" (Summa theologiae, 1, 85, ad 2).

2 De ente et essentia, op. cit., p. 102. 
perfeições"1. No juízo, ser é a realidade tomada nela mesma, que se opõe à realidade representativa ou intencional. O ser é assim a "norma" da verdade.

Mas, sob esse aspecto, na teoria do juízo, a noção de ser não seria identificada com a noção de ente, "o que tem ser"? Sem analisar essa difícil questão, objeto de inúmeros livros e artigos, assinalamos apenas que, do ponto de vista do juízo, é necessário distinguir o que o conceito apreende e aquilo que o juízo, por composição e divisão, significa. Tudo o que é apreendido conceitualmente pelo intelecto envolve a noção de $e^{2} t^{2}$. O ser não é expresso qüididativamente, mas é "apreendido" ou significado pelo juízo ${ }^{3}$, cuja função é a de "pôr" como real (possível ou atual) o que ele significa ou representa.

Alguns enunciados são existenciais (como os de segundo adjacente da forma $S$ é), afirmando ou negando que de fato algo existe. Outros enunciados verdadeiros supõem a existência de algo sem, contudo, afirmá-la (como os enunciados afirmativos de terceiro adjacente da forma $S$ é $P$ ); outros enunciados são verdadeiros e não afirmam nem supõem a existência (como alguns enunciados negativos de terceiro adjacente). Enunciados afirmativos ou negativos são caracterizados pela noção de ser ou de não-ser, enunciados existenciais são caracterizados pela afirmação ou negação da existência ou da atualidade factual do que é mencionado pelo conceito-sujeito. Assim, produzir um enunciado ou significar o ser mediante a produção de um enunciado afirmativo não equivale a afirmar que algo existe. Do ponto de vista da teoria do juízo, ser não tem o mesmo significado de existência.

As distinções de ser, de ente, de essência e de existência que estão envolvidas na análise do juízo tomásica são sugestivas e remetem sua justificação à análise metafísica. Seguindo, assim, certa tradição filosófica, vê-se que a teoria do juízo tomásica pode ser a ante-sala ou "o ponto de partida" da metafísica.

\section{Referências Bibliográficas}

ANSCOMBE, G.; GEACH, P. Three philosophers Aristotle, Aquinas, Frege. Oxford: Basil Blackwell, 1961.

AQUINO, Tomás de. Expositio libri peryermenias. ed. rev. aum. In : Opera Omnia, t. I*1, introdução e notas de R. Gauthier, ed. Leonina. Paris : Vrin, 1989.

Commentaire du traité de l'interprétation d'Aristote. Tradução de B. E.

Couillaud. Paris : Belles Lettres, 2004. Título original: Expositio libri peryermenias.

2 Ver, por exemplo, De veritate, op. cit., q. 1, a.1 ; De ente, op. cit., Prólogo ; Summa theologiae, I, q. 5, a. 2.

3 De trinitate, op. cit., q. 5, a. 3. 
. Summa Contra Gentiles. In: BUSA, R. (Ed.). S. Thomae Aquinatis, opera omnia. Stuttgart: Fromann-holzboog, 1980. v. 2.

. De veritate. In: BUSA, R. (Ed.). S. Thomae Aquinatis, opera omnia. Stuttgart: Fromann-holzboog, 1980. v. 3.

. Première question disputée la vérité. Tradução de C. Brower e M. Peeters. Paris: Vrin, 2002. Título original: De veritate.

. Summa Theologiae. In: BUSA, R. (Ed.). S. Thomae Aquinatis, opera omnia. Stuttgart: Fromann-holzboog, 1980. v. 2.

. L'être et l'essence. Tradução de A. Libera e C. Mychon. Paris, Seuil, 1996. Título original: De ente et essentia.

. Le "de ente et essentia". Edição e tradução de M. Rolland-Gosselini. Paris: Vrin, 1947. Título original: De ente et essentia.

. Librum boethii de trinitate. In: BUSA, R. (Ed.). S. Thomae Aquinatis, opera omnia. Stuttgart: Fromann-holzboog, 1980. v. 4.

. Libros metaphysicorum. In: BUSA, R. (Ed.). S. Thomae Aquinatis, opera omnia. Stuttgart: Fromann-holzboog, 1980. v. 4.

ARISTOTELES. Aristotle categories and De interpretatione. Tradução de J. L. Ackrill. Oxford: Clarendon Press, 2002. Título original: Categoriae et liber de interpretatione.

BÄCK, A. Aristotle's theory of proposition. Leiden: Brill, 2000.

BOYER, C. Le sens d'un texte de St. Thomas, De veritate, q. 1, a. 9. Gregorianum, Roma, v. 5, p. 424-443, 1924.

BROUWER, C.; PEETERS, M. Première question disputée la vérité. Paris: Vrin, 2002.

CAJETANO, Thomas de Vio. Commentary on being and essence. Tradução de L. Kendzierski e F. Wade. Wisconsin: Marquette University Press, 1964. Título original: De ente et essentia $d$. Thomae Aquinatis commentaria.

COUILlaUd, B.; COUILlaUd, M. Commentaire du traité de l'interprétation d' Aristote. Paris: Belles Lettres, 2004.

DAVIES, B. (Org.). Thomas Aquinas. Oxford : Oxford University Press, 2002.

DE FINANCE, J. Cogito cartésien et réflexion thomiste. Paris : Beauchesne,1946.

EDWARDS, S. The realism of Aquinas. In: DAVIES, B. (Org.). Thomas Aquinas. Oxford: Oxford University Press, 2002. p. 97-115.

FERRER, V. Tractatus de suppositionibus. Stuttgart: Frommann-holzboog, 1977.

FOREST, A. La structure métaphysique du concret. 2e. ed. Paris : Vrin, 1956.

GARCEAU, B. Iudicium. Paris : Vrin, 1968.

GEACH, P. Form and existence. In: ___ God and soul. Londres: Routledge \& Kegan Paul, 1969. p. 42-64.

. Reference and generality. Ithaca: Cornell University Press, 1968.

GILSON, E. Being and some philosophers. 2nd ed. Toronto: Pontifical Institute of Oriental Studies, 1953. . L'être et l'essence. Paris : Vrin, 1948. 
LIBERA, A. de. La querelle des universaux. Paris : Seuil, 1996. p. 234.

MARÉCHAL, J. Le point de départ de la métaphysique. 2e ed. Bruxelas : Desclée de Brouwer, 1949.

McINERNY, R. Being and predication. Washington: The Catholic University of American Press, 1986.

OWENS, J. The accidental and essential character of being. In: CATAN, J. (Org.). St. Thomas Aquinas on the existence of God. New York: State University of New York. Press, 1980.

PUTALAZZ, F. Le sens de la réflexion chez Thomas d'Aquin. Paris : Vrin, 1991. ROLLAND-GOSSELINI, M. (Ed.). Le "de ente et essentia". Paris: Vrin, 1947. TONQUÉDEC, J. La critique de la connaissance. 3e ed. Paris : Lethielleux, 1961. VAZ, H. Ontologia e História. São Paulo: Duas Cidades, 1968. p. 67-91. . Síntese. Revista de Filosofia, Belo Horizonte, v. 23, n. 73, p. 159-207, 1996. WEIDEMANN, H. The logic of being in Thomas Aquinas. In: DAVIES, B. (Org.). Thomas Aquinas. Oxford: Oxford University Press, 2002. p. 77-95.

WIPPEL, J. The metaphysical thought of Thomas Aquinas. Washington: The Catholic American Press, 2000. . Metaphysics. In: KRETZMANN, N.; STUMP, E. (Orgs.). The Cambridge companion to Aquinas. Cambridge: Cambridge University Press, 1993. p. 85-127. 